Dr PHILIP CASS is reviews editor of Pacific Journalism Review.

\section{Vital exposé, but it would have been better with more context}

Hit \& Run, by Nicky Hager and Jon Stephenson. Nelson: Potter and Burton. 2017, 159 pages. ISBN 978-0-947-50339-0

$I T \&$ \& $R U N$ tells what happened
when a small group of New Zealand SAS soldiers in Afghanistan decided to mount a revenge raid on two Afghan villages where they thought Taliban were staying, whom they believed had been responsible for the death of one of their own.

With Ministerial approval, relying on faulty intelligence and backed by American firepower, the SAS raided the villages of Naik and Khak Kuday Dad on the night of 22 August 2010. Their Taliban targets were nowhere to be found: they had slipped away into the mountains and were resting peacefully when the SAS arrived by helicopter in the middle of the night.

In the next few minutes, American Apache gunships blasted the villages from end to end, presumably on the direction of SAS forward control officers. The SAS opened fire and by the time it was all over there were six dead men, women and children and 15 wounded. None of them was a member of the

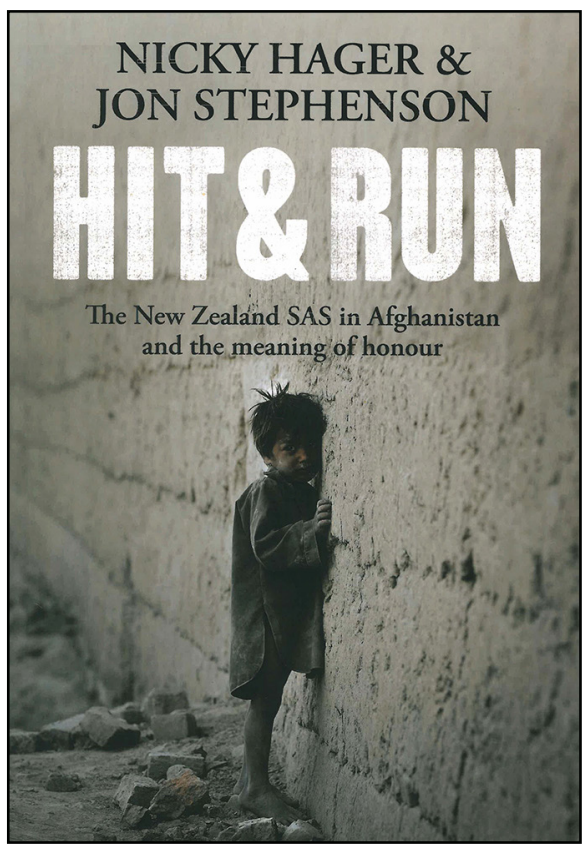

Taliban. Most of them, by all accounts, had not hitherto supported the Taliban, but had offered occasional shelter to family members who were in the Taliban out of a sense of familial duty.

The SAS knew the raid had been a disaster and that they had killed and wounded civilians. It did not, however, stop them later going back to Naik and destroying houses that had been repaired. It was sheer bloody mindedness. The upshot was that the villages now supported the Taliban, who spread their influence throughout the region.

Many of those involved were deeply upset by what had happened. They, presumably, were the ones who later talked to the authors. The SAS high command, on the other hand, immediately began trying to bury the story. They lied when questioned, possibly misled ministers (or if not, those 
politicians may have been guilty of lying themselves) and when war correspondent Jon Stephenson $(2011,2017)$ wrote an article about the incident for Metro magazine, the SAS campaigned for four years in a failed legal attempt to discredit him.

Hager and Stephenson are to be congratulated for exposing all of this and it should be a scandal that the New Zealand SAS was allowed to get away with its mistake for so long. There should certainly be, as the authors say, an enquiry that holds those responsible accountable.

Unfortunately, it is an all too familiar story. If you have small groups of soldiers fighting a guerrilla war in a foreign country where it is impossible to tell the enemy from civilians, then civilians will die unless discipline is extremely tight and where the soldiers have been trained to establish the closest possible relations with locals through a hearts and minds approach.

The SAS in Afghanistan was largely cut off from the locals in their fortified position, something that went against a long established SAS doctrine of winning hearts and minds, a doctrine that required, in Crawford's words, 'actually living among the locals, for sharing their problems and helping them out when it came to planting crops, building and repairing shelters and learning their everyday experience' (Crawford, 1996).

It was a lesson learned from the early days of the Malayan Emergency, during which the New Zealand SAS replaced the Rhodesian C Company and where they gained a good reputation for hearts and minds work (Kemp, 2001).

Hit \& Run is an important book, but it is a very slim volume. It would have been greatly improved if it had looked at more of the history and culture of the family of SAS units in different Commonwealth countries. The SAS has always regarded itself as special and sheltered behind a wall of silence. This cult of secrecy has led to cover-ups of questionable activities, such as the shooting of IRA suspects by a British SAS unit during Operation Flavius in Gibraltar.

Paradoxically, it also contributed to injustices to its own men, such as the failure to award a Victoria Cross to Fijian Corporal Labalaba for his heroic role in the defence of Fort Mirbat in Oman.

It would also have been useful to compare the cover-up of the Afghanistan incident with the Thatcher government's vicious response to ITV's documentary Death on the Rock. Outside the sphere of the SAS, comparisons might also have been drawn with how the My Lai massacre was uncovered.

Given the evidence in the book that the New Zealand SAS handed over a prisoner to an Afghan force known to torture prisoners, it would also have been useful to make comparisons with the controversy in the Australian media over the Vietnam water torture case (Elkins, 1996).

A quibble with the book is the photograph of a child on the front cover. Is he somebody from one of the villages that were attacked? If not, why is he 
there? While it is a striking image it should be clearly identified.

\section{References}

Crawford, C. (1996). SAS encyclopedia. London: Chancellor Press.

Kemp, A. (2001). The SAS. Savage wars of peace 1947 to the present. London: Penguin.

Elkins, A. (1996). Not one scintilla of evidence? The media, the military and the government in the Vietnam water torture case. Australian Journal of Politics and History, 42(3), pp. 345-364.

Stephenson, J. (2017, March 22). Eyes wide shut: the government's guilty secrets in Afghanistan. [First published in Metro magazine, May 2011.] NZ Listener. Retrieved from www.noted. co.nz/currently/politics/eyes-wideshut-the-governments-guilty-secretsin-afghanistan/

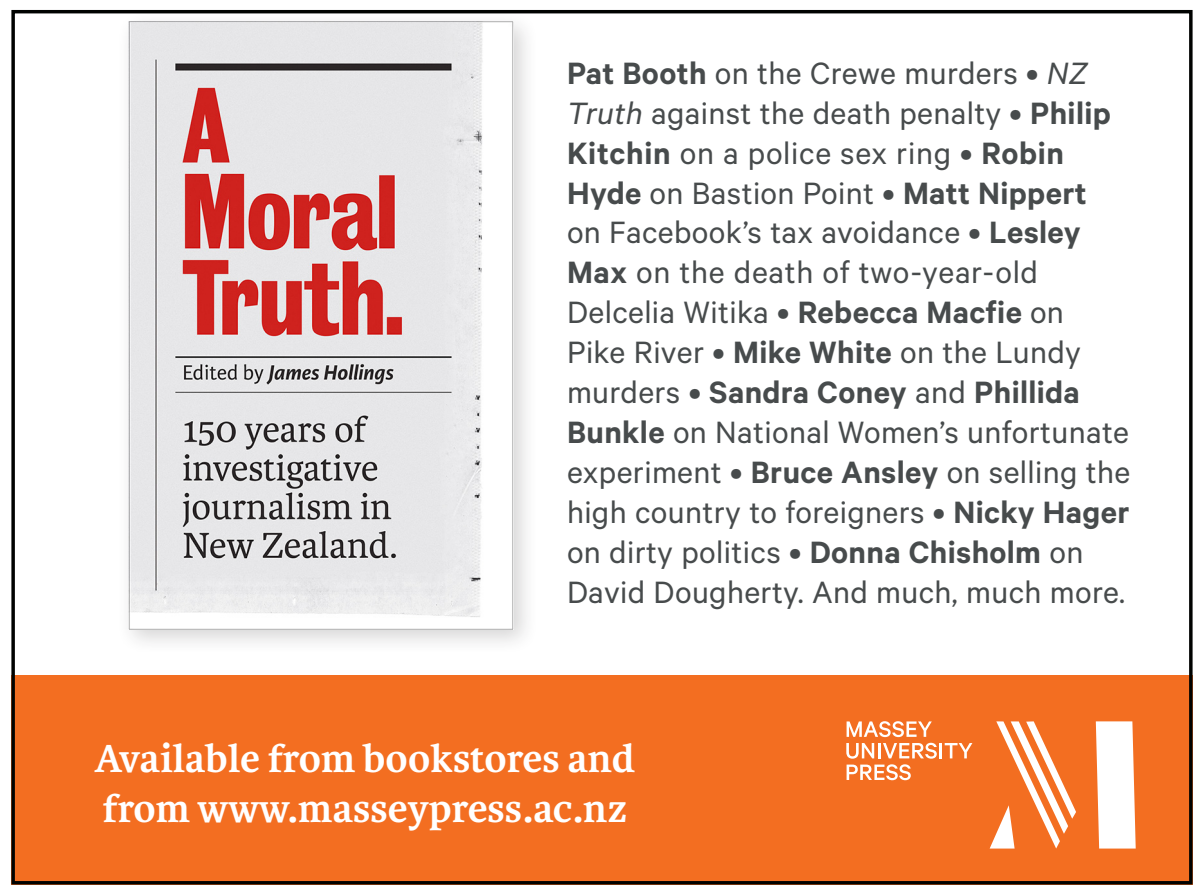

268 PACIFIC JOURNALISM REVIEW 23 (1) 2017 